\title{
Por uma agenda brasileira de estudos sobre implementação de políticas públicas
}

Gabriela Spanghero Lotta

Fundação Getulio Vargas (FGV)

Ana Carolina Nunes

Universidade Federal do $A B C$ (UFABC)

Sergio Cavalcante

Universidade Federal do $A B C$ (UFABC)

Daniela Damiati Ferreira

Universidade Federal do $A B C$ (UFABC)

Juliana Bonat

Universidade Federal do $A B C$ (UFABC)

O artigo tem como objetivo propor uma agenda de estudos no campo de implementação de políticas públicas à luz de análises das lacunas da literatura nacional e das correntes analíticas internacionais. Apresenta, portanto, o estado da arte desses estudos na literatura internacional da última década, a partir do qual são identificadas temáticas que abordam a implementação a partir de diferentes perspectivas e modelos analíticos: accountability e transparência, estruturas de governança, envolvimento de atores não estatais, valores e comportamentos dos burocratas, diferentes níveis hierárquicos da burocracia, discricionariedade e autonomia, resultados de incentivos, estratégias de enfrentamentos de pressões, efeitos sociais da implementação, entre outros. Propõe-se, com base nessa análise, uma agenda nacional que possa se apropriar das temáticas e novos paradigmas e assim aplicá-los às análises das realidades complexas da implementação de políticas públicas no Brasil. Como temas da agenda nacional, propomos: desafios do federalismo brasileiro, implementação em contextos de heterogeneidade e desigualdades, impacto da publicização de serviços, processos participativos e intersetorialidade.

Palavras-chave: políticas públicas, implementação, revisão de literatura, agenda - pesquisa

[Artigo recebido em 22 de outubro de 2017. Aprovado em 3 de setembro de 2018.] 


\section{Por una agenda brasileña de estudios acerca de implementación de políticas públicas}

El artículo tiene como objetivo proponer una agenda de estudios en el campo de análisis de implementación de políticas a la luz de análisis tanto de las lagunas de la literatura nacional y de las diversas corrientes analíticas internacionales. Por lo tanto, presenta el estado del arte de estos estudios en la literatura y en congresos internacionales de la última década a partir del cual se identifican grupos de temáticas que abordan la implementación a partir de diferentes perspectivas y modelos analíticos, desde algunos más tradicionales, influenciados por la administración pública y por la ciencia política, así como enfoques más recientes, de carácter más sociológico. Se propone, con base en este análisis, una agenda nacional que pueda apropiarse de las líneas temáticas y nuevos paradigmas aquí expuestos y pueda aplicarlos a los análisis de las realidades complejas de la implementación de políticas públicas en Brasil. Como temas para la agenda nacional, proponemos: retos del federalismo, implantación en contextos de alta heterogeneidad y diversidad, impacto de subcontratación de servicios, procesos participativos y políticas intersectoriales.

Palabras-clave: políticas públicas, implementación, revisión de literatura, agenda-investigación

\section{For a Brazilian agenda of policy implementation studies}

The paper aims to propose an agenda of studies in the field of public policies implementation analysis based both on the gaps of national literature and international analytical currents. It presents, therefore, the state of the art of these studies in the literature and in international congresses of the last decade from which groups of themes are identified that approach the implementation from different perspectives and analytical models, from some more traditional, influenced by the public administration and by political science, as well as newer, more sociological approaches. Based on this analysis, it is proposed a national agenda that can appropriate the thematic lines and new paradigms exposed here and can apply them to the analysis of the complex realities of the implementation of public policies in Brazil. As issues for the national agenda, we propose: challenges of federalism, implementation in heterogeneous and diverse contexts, impact of outsourcing, participation processes ant cross-sectoral policies.

Key words: public policy, implementation, literature review, agenda - research 


\section{Introdução}

O crescimento dos estudos no campo de análise de políticas públicas tem se baseado no uso de diversos modelos voltados à compreensão, de forma didática, das diferentes fases das políticas, seus atores, decisões e resultados. O modelo do ciclo de políticas, nesse sentido, é usado pela literatura como recurso metodológico eficaz para compreensão dos diferentes tipos de decisões e produtos resultantes de cada etapa da política. A ideia é que as políticas são constituídas de diferentes etapas cronológicas organizadas em: agenda (definição de temas prioritários); formulação (tomada de decisão e planejamento); implementação (execução); e avaliação (verificação dos resultados) (SouZA, 2006). Ao longo dos últimos anos, diversos autores se concentraram em desenvolver modelos analíticos para compreender cada uma dessas fases.

A literatura, no entanto, tem se desenvolvido de forma heterogênea: enquanto as fases de agenda e formulação ganharam espaço na literatura nas últimas décadas, os estudos de implementação se iniciaram posteriormente e ainda têm espaço relativamente restrito, embora em constante crescimento. Apesar do avanço da agenda de estudos de implementação internacional, no Brasil ainda há muito a caminhar para alcançar um corpo robusto de pesquisas sobre o tema. Conhecer a história e os avanços dessa agenda na literatura internacional é o primeiro passo proposto por este trabalho. Em seguida os tópicos abordados internacionalmente são analisados dentro da produção nacional. Por fim, o artigo se dedica a propor uma nova agenda de pesquisas da implementação de políticas públicas no Brasil.

Busca-se aqui, portanto, a partir de uma breve retomada da evolução da literatura internacional sobre implementação e análise das temáticas contemporâneas, propor uma agenda de pesquisas do tema para a literatura nacional que possa subsidiar diversos campos de estudos das Ciências Sociais.

Em termos metodológicos, o artigo foi construído a partir de uma análise dos artigos publicados entre 2003 e 2017 no acervo da Wiley Online Library, onde estão indexadas algumas das revistas mais importantes no campo de Administração Pública, Políticas Públicas e Ciência Política (como Public Administration, Public Administration Review, Governance, entre outras). Foram realizadas buscas com os termos "implementação", "burocracia" e "burocratas" associados a "políticas públicas". Também foram consultados os artigos publicados entre 2003 e 2017 com essas mesmas palavras-chave nas principais revistas brasileiras deste campo, incluindo: Revista de Administração Pública, Revista do Serviço Público, Revista Brasileira de Ciências Sociais, Cadernos Gestão Pública e Cidadania, Brazilian Political Science Review, Organização e Sociedade, DADOS - Revista de Ciências Sociais e Revista Planejamento e Políticas Públicas. Todas as obras foram sistematizadas em 
linhas gerais de análise, metodologia e temas que vêm sendo tratados no campo de estudos da implementação' ${ }^{1}$.

No total, foram identificados 218 artigos internacionais e 21 nacionais. Todos os resumos foram lidos e os artigos classificados nos seguintes grupos temáticos: accountability e transparência (com 20 menções), estruturas de governança (33, sendo 6 nacionais), envolvimento de atores não estatais (7), valores e comportamentos dos burocratas (46, sendo 2 nacionais), diferentes níveis hierárquicos da burocracia (6), discricionariedade e autonomia (18, sendo 6 nacionais), resultados de incentivos (22), estratégias de enfrentamentos de pressões (1), efeitos sociais da implementação (6). Artigos abordando a história e teorias dos estudos da implementação somaram um total de 18 publicações, todos eles pertencentes à literatura internacional. O restante dos artigos (62) englobou temas variados (como estudos teóricos sobre implementação, estudos sobre modelo burocrático, estudos sobre a produção de artigos no campo ou análise de um programa específico denominado "implementação" de forma apenas conceitual, mas não enquanto objeto de estudo) e por essa razão recebeu a classificação de "outros".

\section{Gráfico 1 - Publicações por categorias, literaturas brasileira e internacional}

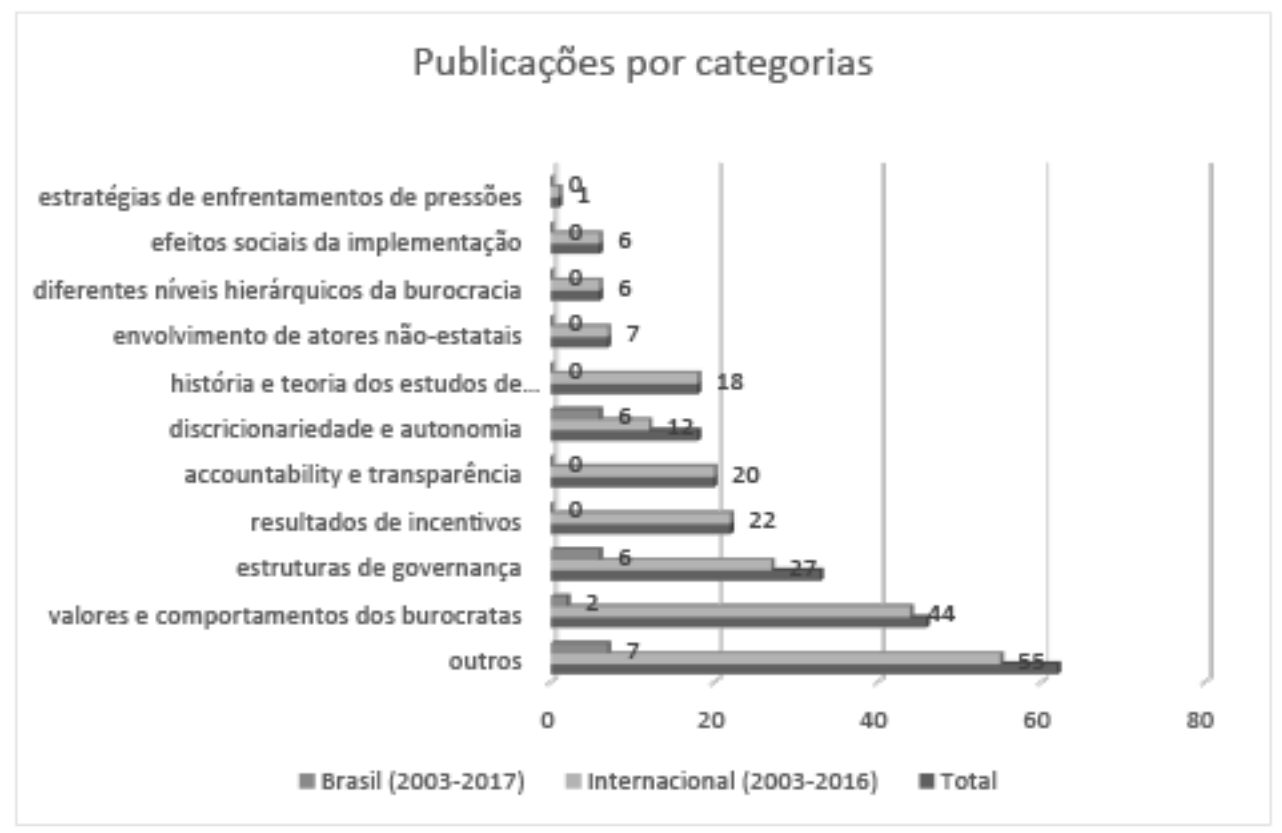

Fonte: elaboração própria.

10 artigo não pretende fazer uma síntese de toda a produção realizada, mas sim das linhas gerais de pesquisa e abordagens metodológicas recentemente incorporadas. 
$\mathrm{Na}$ agenda brasileira, os estudos de implementação de políticas públicas encontrados no período selecionado se dividiram principalmente em três categorias. Há artigos voltados para os burocratas de nível de rua, seja enfocando sua discricionariedade e autonomia nos processos de implementação, seja enfocando seus valores e comportamentos que pautam a implementação das políticas. Outros artigos jogam luz sobre as diferentes estruturas de governança presentes na implementação de políticas públicas, que podem englobar tanto arranjos institucionais das políticas públicas, bem como a relação entre camadas federativas envolvidas na implementação. Por fim, há estudos de caso de políticas e programas específicos, os quais são analisados à luz dos modelos e do arcabouço teórico de implementação de políticas públicas, que foram reunidos na categoria "outros".

\section{Gráfico 2 - Artigos da literatura brasileira}



Fonte: elaboração própria.

Foram lidos os resumos de todos os artigos e selecionados para leitura completa e síntese cerca de 40 deles, que contemplavam todas as temáticas encontradas. Também foram lidas outras referências importantes da área, como livros e outros artigos mais citados (a exemplo de LIPSKY, 2010; DUBOIS, 1999; MAYNARD-MoOdY; MUSHENO, 2003). Assim, além de apresentar esses avanços analíticos internacionais, o artigo realiza uma reflexão ainda exploratória sobre as possíveis ressonâncias dessas temáticas à agenda nacional. Considera-se que a fase de implementação reserva uma série de oportunidades para a compreensão das estruturas, instituições, processos e valores das políticas públicas. Daí a importância de ampliar o olhar dos pesquisadores e não a tratar como uma mera etapa de execução. 


\section{Breve história dos estudos de implementação}

O estudo da implementação de políticas públicas ganha força conforme emerge a atenção sobre o desempenho do Estado e de suas ações. Em Implementation Studies: time for a revival?, Susan Barrett (2004) narra a evolução dessa agenda de pesquisa a partir da sua própria trajetória profissional. Nos anos 1960, ela destaca, as ferramentas de planejamento estratégico avançam dentro da temática de gestão pública, bem como o fortalecimento da capacidade de governos locais. Tanto essa década quanto a seguinte são marcadas pelo reforço da pauta da eficiência das políticas públicas e aprimoramento dos mecanismos de governança e inovação. Nessa nova pauta, enquanto os estudos da área de políticas públicas ainda tomavam forma, a implementação apareceu na literatura como adjacente às pesquisas em administração e gestão pública que visavam ao fortalecimento da capacidade estatal.

A mudança desse foco nos resultados das políticas públicas viria a partir do estudo clássico de Pressman e Wildavsky (1984), que apresentou a complexidade dos processos de interpretação e tradução das ideias concebidas na etapa de formulação da política em resultados de implementação, que são distintos entre si.

A literatura dos anos 1970 até o início da década seguinte trata a implementação como um dos passos do processo de produção das políticas públicas, que tem por princípio seguir as regras administrativas e respeitar a ordem hierárquica do processo. Conhecida como abordagem top-down, considera que a política pública é formulada no topo da hierarquia das agências públicas, legitimada pelo grupo político que as comanda e, então, traduzida em instruções aos níveis hierárquicos abaixo, até atingir o público beneficiário.

A preocupação com a implementação entraria, portanto, junto ao olhar sobre a efetividade das políticas públicas, buscando responder a perguntas como: em que fase desse processo de tradução da política pública há falha ou desvio nas instruções?

Entende-se, por essa perspectiva, que o controle do processo de implementação por parte do topo da hierarquia é valorizado como forma de manter as políticas públicas o mais próximo possível de suas concepções iniciais. Nesse sentido, a discricionariedade é tida como um "fator desviante" da finalidade da política pública, que pode afastá-la de seus objetivos iniciais.

Em Policy and Action, Barrett e Fudge (1981) sugerem que a implementação deve ser considerada como parte integrante dos processos da política pública. Mais do que simplesmente uma fase administrativa, a implementação também envolve processos de barganha e negociação. Tal concepção reforça que a negociação das ideias não é exclusiva da fase de formulação e sugere 
a necessidade de proteger os valores e interesses da política pública nas demais fases. Elmore (1979), Hjern e Porter (1981) defendem que o processo de implementação tem tanta complexidade nos relacionamentos e interações que não faz sentido relacionar a "ação" da política pública à avaliação do cumprimento de seus objetivos.

Essa perspectiva analítica é uma virada, por afastar o foco dos mecanismos de controle top-down e direcioná-lo às estruturas de poder e de negociação de interesses entre os diferentes atores envolvidos na implementação. É onde se enquadra, por exemplo, a proposta de Lipsky (1980) de analisar a burocracia de nível de rua como arena do poder discricionário que determina resultados das políticas públicas.

E uma vez que os agentes implementadores estão sujeitos a múltiplas pressões, os estudos sobre a implementação deveriam considerar essas interações. Isso significa iniciar a análise pela entrega dos resultados da política pública e, a partir deles, compreender as diferentes interações que aconteceram para que se chegasse àquele ponto. Essa é a abordagem conhecida como bottom-up, que compreende a estrutura de implementação de baixo para cima (HJERN; PORTER, 1981).

No começo dos anos 1980, o debate se polarizou entre as abordagens top-down e bottom-up, o que também reflete diferenças conceituais e ideológicas sobre o papel do Estado e a necessidade de controle da coisa pública. Por um lado, o objetivo intrínseco à abordagem top-down é identificar as falhas no controle que levam a problemas na execução e, consequentemente, impossibilitam a consecução dos objetivos da política. Por outro, a abordagem bottom-up busca entender as evoluções pelas quais a política pública passa no decorrer do seu processo de implementação, considerando o ambiente, as relações e o comportamento dos atores envolvidos.

Embora a polarização do debate entre as duas abordagens tenha se esgotado, ele trouxe à tona uma série de questões importantes. Uma delas é a função dos estudos de implementação: deve-se buscar respostas sobre como evitar falhas nos processos das políticas públicas ou compreendê-las como parte do processo? Enquanto defensores da abordagem top-down acreditavam que a abordagem oposta falhava em não propor melhor desenho às políticas, os defensores da abordagem bottom-up questionavam se isso era possível sem entender a realidade dos processos das políticas públicas.

Uma terceira geração de estudos de implementação, ainda nos anos 1980, busca sintetizar elementos das abordagens top-down e bottom-up e focar na dialética das relações entre ideias e ação das políticas públicas (SABATIER, 1988; GoGGIN et al., 1990; PALUMBO; CALISTA, 1990 apud BARRETT, 2004). 
Já a partir do fim dos anos 1980, o contexto de contingência financeira e necessidade de maximizar eficiência dos gastos públicos pautou o avanço da agenda de New Public Management (NPM). Até o fim da década de 1990, essa agenda se tornaria o paradigma normativo da administração pública, centrando no debate do campo as reformas gerenciais com vistas à maior eficiência do Estado e, portanto, melhores resultados de implementação (AUCOIN, 1990; DAWSON; DARGIE, 1999).

Essa agenda "gerencialista" trouxe ideias da gestão privada para dentro da administração pública, como redução do Estado, corte de gastos, privatização e desregulação. Há, portanto, uma pressão para que a literatura se debruce sobre novos temas, focados nesses novos paradigmas em disputa e construção. $O$ impacto dessa nova agenda dominante sobre os estudos de implementação aparece no apelo por melhores resultados e por processos mais enxutos e rastreáveis. Seu legado foram modelos de implementação que envolvem a pressão por atingir resultados pré-determinados e até mesmo ferramentas que acabam modificando a natureza das políticas públicas para que elas se conformem com as expectativas de desempenho. Para os estudos de implementação, a consequência mais nefasta pode ser a de ignorar a complexidade das instituições e das relações entre atores.

Os estudos de implementação, nesse sentido, estão tensionados entre a busca por melhor controle das políticas públicas e seus resultados e a melhoria dos serviços e do desempenho do Estado de maneira geral e o entendimento da realidade da micropolítica entre e dentro das organizações e sua influência no processo de implementação.

Barrett (2004), ao realizar uma síntese e análise da literatura de implementação, advoga pela necessidade de renovar a ênfase em um trabalho interdisciplinar nos estudos de implementação, observando tanto a discussão sobre sua natureza (conceitual) quanto a realidade dos processos (empírico). A autora também reforça a necessidade de abordar o paradoxo central entre controlar os processos e garantir autonomia aos implementadores para atingir os objetivos desejados e de não perder de vista a relação entre esses temas e ética, responsabilidade social, accountability.

Além de Barrett, diversos outros autores realizaram, no início dos anos 2000, sínteses da literatura de implementação. A conclusão geral é de que houve, ao longo dos anos, um descrédito dos estudos de implementação, que se tornaram fora de moda.

Saetren (2014) analisa a produção da literatura e demonstra que essa suposta redução de estudos aconteceu nas revistas mais centrais de Administração Pública (AP) e Políticas Públicas (PP), mas não nas revistas setoriais. Ou seja, enquanto os estudos de implementação saíram de moda nas principais publicações de PP e AP, eles foram crescentes nas revistas de saúde, educação, estudos do direito, entre outras. 
Analisando os motivos para a baixa na produção de implementação, Saetren (2014) chega a motivações como: o debate estéril entre o top-down e o bottom-up; as mudanças nas relações entre Estado e sociedade; os problemas pelo excesso de variáveis pouco sistematizadas pela literatura, entre outros. Esses motivos, argumenta Saetren (2014), teriam levado a um descrédito temporário dos estudos de implementação, mas que, segundo ele, deveriam ser retomados, dado inúmeras questões continuarem sem respostas pela literatura.

\section{Agenda internacional de estudos sobre implementação}

A análise da produção dos últimos 15 anos (2003-2016) demonstra que houve um deslocamento analítico nos estudos de implementação. Da dicotomia entre modelos top-down e bottom-up às análises mais gerencialistas, os anos 2000 retomam os estudos de implementação com uma nova pauta voltada a compreender, de forma mais profunda e sistemática, os processos de implementação e sua implicação em temáticas específicas que ganham espaço nas agendas governamentais.

Dentro da agenda atual de estudos sobre implementação, há uma grande variedade de enfoques analíticos, desde aqueles que observam as estruturas de implementação, numa abordagem mais institucionalista, até aqueles que observam valores e posições sociais dos implementadores, numa perspectiva mais voltada à agência dos indivíduos e com inspiração sociológica. Tradicionalmente, grande parte da agenda recebeu influência da Ciência Política e da Administração Pública, que instigaram preocupações distintas e, frequentemente, complementares. No entanto, os campos de estudos de implementação mais recentes têm devotado sua atenção para aspectos mais sociológicos do processo e, portanto, distanciamse do campo da Administração Pública. Influenciados pelos outros campos, tratam de assuntos que, embora estivessem presentes desde a origem dos estudos de implementação, não eram objetos centrais de análise até então.

Além disso, alguns paradigmas são tidos como dados na literatura, que passa a incorporar alguns pressupostos importantes. O primeiro deles é a ideia de que estudos de implementação não devem ser vistos como uma fase específica e pósformulação. A literatura passa a compreender a implementação como um conjunto de processos decisórios contínuos que passam por diversos atores e organizações como uma cadeia de tomada de decisões. Isso torna-se mais evidente quando são introduzidos os temas de governança multinível que deslocam os espaços de decisão sobre a implementação para diversas instâncias decisórias em uma cadeia contínua. Junta-se a isso a ideia de que as decisões não são tomadas por atores individualmente, mas sim em processos interativos constantes, entre atores de organizações diferentes ou entre burocratas e usuários. A ideia de implementação 
enquanto interação ganha um espaço grande na literatura contemporânea.

Disso decorre um segundo pressuposto: decisões são tomadas constantemente durante a implementação. Agentes implementadores não são simples seguidores de regras, eles as interpretam, alteram e decidem. A questão da discricionariedade ou agência se torna central para compreender os processos de implementação. É com base nesse pressuposto que crescem os estudos voltados a compreender a discricionariedade e os processos de responsabilização e accountability dos implementadores.

Por fim, outra característica importante dessa literatura contemporânea é sua aproximação com a literatura de burocracia de nível de rua - originalmente mais situada nos estudos organizacionais. Atualmente, a maior parte da literatura produzida incorpora olhares para os burocratas implementadores para compreender como se dão os processos decisórios da implementação.

Tendo como base esses pressupostos da literatura, ela passa a abarcar um conjunto de novas temáticas que ganham a agenda, como: accountability, transparência, discricionariedade e autonomia, representação burocrática, implementação e desigualdades, entre outras. A seguir trataremos de grupos de temáticas mais relevantes que têm aparecido na literatura internacional e que podem servir de inspiração para o aprofundamento da literatura brasileira.

\section{Estudos voltados à accountability dos implementadores}

Ligado à administração pública, este campo segue uma lógica analítica e teórica baseada na ideia de comando e controle, transparência e responsabilização. Partese do pressuposto de que, em uma democracia, o governo é composto tanto por representantes eleitos, que tomam decisões, quanto de atores estatais não eleitos, mas que também tomam decisões. A questão central que se busca responder é: dado que representantes eleitos e não eleitos tomam decisões, como pode haver uma responsabilização (accountability) da decisão de um representante estatal que não foi eleito democraticamente?

Nos anos 1980, a resposta recaía sobre mecanismos hierárquicos de comunicação e controle, visando minimizar as decisões dos burocratas hierarquia abaixo, conforme pregava o modelo top-down, hegemônico na época. Segundo Hupe e Edwards (2012), esses conceitos mais tradicionais de accountability são relacionados diretamente com a tradição da democracia representativa. Todavia, com o crescimento das novas formas de governança, é preciso pensar em definições mais ampliadas desse conceito. Mais recentemente, passou-se a entender que essas decisões dos burocratas implementadores não podem ser eliminadas. Assim, a preocupação deixou de ser a limitação das decisões dos burocratas, e sim a responsabilização de suas decisões. 
Há uma linha de estudos que se aprofunda sobre maneiras de responsabilização dos implementadores, considerando que um dos principais desafios das democracias contemporâneas é justamente equacionar o dilema entre a necessidade de controle da atuação do Estado e a premência de se expandir a capacidade de suas burocracias (Bevan, 2015; Ahn; Bretschneider, 2011; Mingus, 2008; Hupe; Hill, 2007; Peters, 2010; JARVIS, 2014; BARRETT, 2004; WIMBuSh, 2011). Segundo Pires (2009, p. 148), central a esse dilema está o poder discricionário dos atores implementadores, o qual tanto é foco das investidas de controle como também confere aos burocratas a capacidade de inovar e identificar as melhores soluções para os problemas. Isto posto, a análise das alternativas de gerenciamento da discricionariedade é fundamental para a compreensão das condições e estruturas em que se dão a implementação de políticas em contextos democráticos.

A literatura atual tem buscado avançar na análise e proposição de sistemas de institucionalização de uma accountability direta no processo de implementação, baseada em um movimento triplo: de tornar os funcionários públicos de indiretamente a diretamente responsáveis; da política para instituições públicas; e, por último, de instituições públicas para a opinião pública, reforçando, assim, a democracia associativa (Hupe; Edwards, 2012; Behagel; ARTS, 2014; Chen, 2013; BeERI, 2013).

\section{Estudos sobre estruturas de governança voltadas à implementação}

Diretamente ligado ao anterior, este campo surgiu após a identificação da complexidade do processo de implementação, envolvendo um grande número de atores, agências e organizações, com a compreensão de que, também, as decisões não são tomadas pelo Estado sozinho. Essa linha procura responder às seguintes questões: qual o conjunto de organizações e atores envolvidos na implementação, quais suas responsabilidades, influências e relações formais e informais?

Há aqui dois enfoques analíticos distintos. Parte da literatura se situa no campo organizacional e analisa as estruturas de governança organizacionais, procurando compreender que organizações interagem no contexto de implementação, tendo como base lógicas como a implementação multinível, mecanismos de coordenação, governança entre outros (ZUBEK; STAROŇOVÁ, 2012; EWALT; JENNINGS JR., 2004; Goldfinch; DeRouen JR.; PospiesznA, 2013; YesilKagit; ChRISTENSEN, 2009; BRyson; Crosby; Stone, 2006; Meier; O’Toole, 2006; Scott, 2006; Jones; Noble, 2008; SAger et al., 2014; CucCINIELlo et al., 2015). Uma segunda parte da literatura analisa as estruturas de governança no nível dos atores, buscando compreender, por exemplo, como as redes sociais dos burocratas afetam a sua atuação (HEEKS; STANFORTH, 2014; Wang; Chen; Berman, 2016; PApadopoulos; Merali, 2008; SutCliffe, 2007).

Na primeira perspectiva, uma importante abordagem que enfoca a participação 
de múltiplos atores na implementação é a teoria ator-rede (actor-network theory - ANT), que trata sobre o poder e os mecanismos da prática de uma política, relacionando as redes internas e externas existentes em sua produção (BRYSON; CRosby; BRYSON, 2009; LAW; CALLON, 1992).

Na segunda perspectiva, trabalhos como os de Marques (2003), Lotta (2015), Lotta e Pavez (2010), entre outros, têm analisado as dimensões interativas e relacionais da implementação compreendendo esse processo como dinâmico e variável. Marques (2003, p. 22) afirma que no "funcionamento concreto da política, os contatos institucionais são canalizados por contatos pessoais e institucionais que se apoiam em padrões de relações preexistentes e ajudam a recriá-los". Essas estruturas canalizam informações, apoios, alianças e a formação de projetos e visões que influenciam a formação de preferências e constrangem escolhas, estratégias e alianças. É baseado nessa perspectiva que os autores mencionados acima avançam em análises do processo de implementação a partir do mapeamento das redes de relações dos atores implementadores, observando a implementação a partir das suas estruturas relacionais.

\section{Estudos sobre processos de implementação por atores não estatais}

Outro campo na agenda de pesquisa contemporânea tem como objeto de estudo as organizações não estatais implementadoras de políticas, sejam elas privadas ou públicas não estatais. O foco analítico é entender se existem diferenças entre a implementação de políticas feitas diretamente pelo Estado e por agentes não estatais, quais são essas diferenças e entender por que elas existem ou não. Parte da literatura tem denominado essas organizações de government-organized non-governmental organization (GONGO), argumentando que sua existência é determinada pela interação que estabelecem com o Estado e, portanto, a determinação das fronteiras de ambos se daria justamente pelos processos interativos estabelecidos nessa relação contratual (SHARMA; GUPTA, 2009; SHEA, 2011).

A compreensão da disputa de valores, fronteiras e práticas entre Estado e organizações não estatais é uma das dimensões importantes desses estudos (SHARMA; GUPTA, 2009). Outra dimensão é a compreensão dos resultados das políticas, analisando se haveria diferenças em termos de eficiência e eficácia nas políticas providas por atores não estatais.

Para essa literatura, o processo de implementação por atores não estatais é de outra natureza, visto que, diferentemente dos burocratas que devem agir de acordo com o previsto na lei, atores não estatais são elegíveis para implementar políticas públicas exatamente por sua experiência ou capacidade de inovar em determinadas áreas. Por outro lado, quando há a implementação por múltiplos atores, não fica 
muito claro ao cidadão quem é o responsável por assegurar determinado direito, diferente de quando acontece a implementação direta por organizações estatais.

Assim, embora a literatura reconheça essas diferenças na implementação por atores estatais ou não estatais, o resultado esperado com a implementação de determinada política é visto, em termos normativos, como sendo o mesmo: a garantia do acesso a direitos, por meio de serviços ou benefícios. E como há diferenças nos processos de implementação, o sistema de controle da implementação também deve ser diferenciado, não obstante seu objetivo final ser o mesmo. Nesse sentido, a literatura avança na compreensão de sistemas de controle que considerem, de um lado, as diferenças de natureza das organizações e, de outro, a expectativa de resultados semelhantes pelas políticas públicas.

\section{Análises sobre valores e comportamentos dos burocratas no processo de implementação}

Parte da literatura tem aprofundado na compreensão de como os valores dos burocratas, suas agências ou profissões afetam suas decisões, focando em três elementos distintos: a ideia de representatividade burocrática, a de valores e de profissões e, por fim, a de ativismo institucional.

A representatividade burocrática se refere a uma burocracia que reflete o perfil da população como um todo, incluindo grupos considerados em desvantagem ou minoria (GROENEVELD; VAN DE WALLE, 2010). A teoria da burocracia representativa sustenta que o histórico sociodemográfico dos servidores públicos é importante, pois afeta seus valores, que, por sua vez, influenciam sua tomada de decisão administrativa. Andrews et al. (2016) defendem que dois pressupostos estão subjacentes a essa teoria. A primeira suposição é que, através de processos de socialização, indivíduos com o mesmo perfil sociodemográfico compartilharão certos valores. A segunda é que os burocratas agem de acordo com seus valores e tentam maximizar os valores que Ihes são salientes na hora da decisão (SoWA; SELDEN, 2003; LOTTA, 2015).

Uma discussão central na teoria da representação burocrática é a distinção entre representação passiva e representação ativa. A primeira ocorre quando os servidores públicos refletem o perfil sociodemográfico da população para quem eles prestam serviços, incluindo grupos minoritários e/ou desprivilegiados. A segunda ocorre quando esses servidores, além de refletir o perfil da população na qual estão inseridos, também agem ativamente para representar esses grupos (MOSHER, 1982).

Todavia, essa literatura está sujeita a diversos embates. De um lado, autores apontam que a representatividade levaria a uma maior identificação entre burocratas e população, ampliando a confiança nas ações estatais, além de oferecer 
carreiras do setor público para determinados grupos que, de outras formas, teriam dificuldade de acesso a tais espaços de poder. Por outro lado, autores argumentam que a representatividade possui potencial de aumentar práticas clientelistas e de patronagem. Não se pode negar ainda que a lógica da representação também entra em conflito com os princípios isonômicos e impessoais do Estado (KIM, 1994; SoWA; Selden, 2003; Bradbury; Kellough, 2011, Andrews et al. 2016; LotTA, 2015; PAVeZ, 2006; LIM, 2006; MEIER; NICHOLSON-CROTTY, 2006; SAIDEl; LOSCOCCO, 2005; WILKINS; Williams, 2008; Kasymova, 2015; BaILEY, 2004; BuRNS; BRAdBuRY, 2013).

Outro conjunto de autores tem analisado os valores nas decisões dos burocratas. Argumenta-se que as decisões dos atores estatais são permeadas de valores individuais, de seus pares, de suas agências e de suas profissões. Esses valores e preferências são conformados por diversos tipos de influências, tais como os treinamentos profissionais, as relações que estabelecem com seus clientes e pelas próprias instituições onde eles estão inseridos (LIPSKY, 2010). A consciência do que influencia os valores e preferências dos atores estatais é importante, uma vez que "os burocratas precisam coordenar seus próprios valores com os valores de diversos atores envolvidos na implementação, para conseguirem operar suas ações" (LOTTA, 2015, p. 58).

Por fim, uma terceira perspectiva analítica parte da ideia de ativismo institucional. Esse ativismo se refere às práticas realizadas por um agente público no interior do Estado, que "visa a promover projetos políticos ou sociais percebidos pelo ator como de natureza pública ou coletiva" (ABERS, 2015, p. 148). Tais práticas são "adotadas por servidores públicos e realizadas de dentro do Estado ou a partir de informações, instrumentos ou contatos obtidos nele, com o intuito de promover projetos, políticas ou agendas de natureza pública e que estejam alinhados aos valores destes mesmos burocratas" (FERREIRA, 2016, p. 64).

As questões da representatividade, dos valores e do ativismo são, em suma, características individuais dos burocratas que influenciam suas ações práticas nos processos de implementação. No entanto, é pertinente observar outros elementos que também influenciam a implementação de políticas, como a hierarquia, gerência, liderança e criatividade.

\section{Análise da influência de outras camadas burocráticas na implementação}

Outro campo de estudos parte do entendimento de que existem vários níveis ou hierarquias diferentes de discricionariedade na cadeia de implementação de políticas públicas. Um pressuposto importante dessa linha é que não se pode compreender a implementação sem considerar elementos - entre eles, a discricionariedade - de outras camadas da implementação. Em outras palavras, 
a literatura se volta para a influência de outras camadas burocráticas envolvidas no processo de implementação e busca se aprofundar sobre em que camada foi tomada a decisão que pode ter sido passada adiante na cadeia de implementação.

Por muito tempo, o nível da rua foi objeto de estudos e preocupações. Nos últimos anos, todavia, a literatura tem compreendido que olhar para uma camada acima também é importante. Daí o surgimento de estudos recentes que abordam a burocracia de médio escalão - os gerentes - e procuram entender como ela afeta a liberdade e discricionariedade no nível da rua.

Essa literatura analisa a atuação da burocracia de médio escalão buscando compreender seu papel como um o elo entre o alto escalão e os executores das políticas. Considera-a, portanto, como ator central que pode conectar o processo de formulação ao de execução, ou, ainda, faz a tradução entre os elementos políticos e técnicos envolvidos nas políticas públicas (CAVALCANTE; LOTTA, 2015). As análises dessa literatura estão buscando compreender diversas dimensões da atuação desses burocratas, considerando centralmente: funções e lugares (VIE, 2010; LEWIS, 1992; THOMAS; LINSTEAD, 2002), seus papeis (MINTZBERG, 1973; CHAREANPUNSIRIKUL; WOOD, 2002; VIE, 2010; CURRIE; PROCTER, 2005), seus comportamentos, valores e motivações (GAINS; JoHn, 2010; WITESMAN; WALTERS, 2013; MeYER et al., 2014; JACOBSON, 2011; FLOYD; WOOLDRIDGE, 1992) e com quem se relacionam e como suas relações determinam resultados de políticas (KURATKO et al., 2005; HUISING; Silbey, 2011; KeISER, 2010; AleXANDER; Considine, 2011).

\section{Estudos da compreensão da discricionariedade}

A literatura tem feito uma distinção entre o espaço existente para a discricionariedade - o qual é ditado por regras formais e informais - e o exercício da discricionariedade que acontece nesse espaço. Tal distinção parte do pressuposto de que os indivíduos, ainda que sujeitos a um mesmo espaço para o exercício da discricionariedade, não necessariamente a exercem da mesma forma ou na mesma intensidade.

De um lado, a pesquisa do espaço para a discricionariedade avalia a sua extensão. De outro lado, a pesquisa sobre o exercício da discricionariedade investiga o que influencia os atores a agirem de uma forma ou de outra, e, para tal, os valores dos atores, suas relações sociais, suas interações e suas corporações são utilizados como recursos para responder a essa questão. Na pesquisa sobre o exercício da discricionariedade podem ser utilizados, também, os recortes envolvendo as diferentes camadas burocráticas mencionadas anteriormente.

Com relação ao exercício da discricionariedade, um conjunto de trabalhos tem buscado mapear as chamadas "práticas" de ação da burocracia, compreendendo que há determinados padrões de ação que podem ser levantados, analisados 
e compreendidos, possibilitando, inclusive, tipologias de ação ou tipologias de perfis de burocratas. Esse tipo de análise aparece especialmente nos estudos setoriais que observam como se deu o processo de implementação em políticas específicas, nos quais se busca compreender fatores de sucesso e fracasso e formas de implementação categorizadas em práticas (STRUYK, 2007, analisando fatores e sucesso e fracasso; Henderson, 2013, analisando implementação de políticas de saúde; PIOTROWSKı et al., 2009, analisando implementação de políticas de governo aberto; HAEDER; WeIMER, 2013, analisando políticas de assistência; BRoOK; KING, 2011, com políticas de seguridade; HICKS, 2014, políticas de educação; PINTO; Oliveira, 2008; e SANTIAGo, 2017, políticas ambientais).

\section{Análise dos resultados de incentivos à atuação dos burocratas na implementação}

Outro campo, filiado à administração pública, procura entender se determinados incentivos alteram o exercício da discricionariedade dos burocratas de nível de rua. Essa linha trabalha a partir da teoria do agente-principal, que supõe que comandantes e comandados possuem diferentes desejos e objetivos e, consequentemente, problemas de coordenação surgem a partir do descompasso desses desejos e objetivos distintos. A partir desse pressuposto, verifica-se se um determinado incentivo aumenta a adesão em comando e obediência. Essa linha pode analisar tanto a influência dos incentivos no campo individual como no campo das organizações.

A existência de controle gerencial, gerenciamento de desempenho e vigilância externa seria crucial para o funcionamento de um sistema de incentivos e sanções no campo das organizações (HARRISON, 2015). Para Lipsky (1980, p. 161), a fim de se viabilizar o maior controle e a maior uniformização da atuação dos burocratas de nível de rua, as organizações devem: conhecer o que esperam que seus funcionários façam; conhecer como medir a performance deles; ser capaz de compará-los entre si e ser capaz de usar incentivos e sanções capazes de discipliná-los.

A literatura tem apontado o pagamento por desempenho como um fator que pode propiciar um maior controle hierárquico da atuação dos burocratas de nível de rua. Para que esse incentivo seja efetivo, entretanto, alguns procedimentos e mecanismos são necessários, tais como: a definição de objetivos de desempenhos claros; a elaboração de indicadores de gestão, o atendimento feito com base em roteiros pré-estabelecidos no nível macro da política e o preenchimento de sistemas eletrônicos (HARRISON, 2015). Possíveis problemas causados pelo aumento do controle dos burocratas de nível de rua com base no uso de incentivos seriam: o aumento do uso de medidas quantitativas por esses burocratas pode levá-los a deixar questões complexas de lado; há a perda de sua capacidade em realizar a racionalização dos atendimentos no caso de excesso de demanda pelo serviço, 
ocorrendo a transferência desse procedimento para os formuladores, o que nem sempre é legítimo do ponto de vista político (HARRISON, 2015).

\section{Análise das estratégias de enfrentamento das pressões (coping)}

Outra abordagem dos estudos analisa as estratégias de enfrentamento das pressões dos burocratas de nível de rua. Essa linha de pesquisa parte do pressuposto de que esses burocratas enfrentam dois tipos diferentes de pressões no exercício de sua profissão. De um lado, os usuários das políticas demandam um atendimento personalizado. Do outro, o Estado demanda um atendimento mais produtivo, padronizado e eficiente.

A literatura constatou que os burocratas lidam com essa dupla pressão através de estratégias de fuga - chamadas de estratégias ou mecanismos de coping por Lipsky (1980). Exemplos desses mecanismos incluem o atendimento indiferente por parte dos burocratas, a transferência de responsabilidades (ou culpabilização) e a criação de metas modestas a serem atingidas, entre outros.

Desde o trabalho de Lipsky (1980), a literatura tem identificado uma série de diferentes mecanismos criados pelos burocratas para lidar com as pressões do trabalho, situações conflituosas e demais dificuldades inerentes ao seu contato com os cidadãos. Esses mecanismos de coping foram catalogados em três tipos distintos: os que se aproximam dos clientes, os que se afastam dos clientes e os que vão contra os clientes (TUMMERS et al., 2015).

Entre as estratégias que se aproximam dos clientes, estão os atos de contornar as regras, dar maior atenção a um grupo ou indivíduo específico, usar recursos pessoais, criar ações instrumentais e até mesmo quebrar regras em favor de uma clientela. O burocrata pode ajustar ou contornar as regras de modo a favorecer as demandas de sua clientela que não estejam de acordo com as regras da política. Outra estratégia é a atenção privilegiada a um grupo específico em detrimento de outros - embora essa prática seja questionável quanto ao fato de aproximar os burocratas de seus clientes. Burocratas também tomam ações instrumentais, focadas na criação e execução de soluções de longo prazo, para superar situações de estresse. Por fim, outra estratégia identificada pela literatura é o investimento de recursos pessoais dos burocratas, além dos especificados em suas funções.

As estratégias que afastam os burocratas dos cidadãos podem ser listadas como os atos de rotinização do serviço, o racionamento do serviço e até mesmo a fuga do contato com os clientes. Ao lidar de maneira padronizada com os clientes, os burocratas evitam situações em que seja necessário o seu julgamento pessoal e, assim, evitam situações potencialmente estressantes. O racionamento do serviço diz respeito à dificuldade de acesso criada pelos burocratas e imposta aos clientes 
e acontece sobretudo quando as cargas de trabalho dos burocratas são altas e eles possuem alto poder para definir (ou promover) o acesso a benefícios.

Por fim, das estratégias que vão contra a clientela, fazem parte a aderência rígida às regras, o confrontamento com os clientes e, também, casos em que há a quebra da regra contra os clientes. A aderência inflexível às regras é uma maneira de impor sanções a clientes, sobretudo os mais manipulativos ou exigentes. 0 confrontamento, ou a reação agressiva ao contato dos clientes, é também uma estratégia dos burocratas de lidarem e responderem a contatos e/ou clientes agressivos - embora também haja estudos que mostrem que a agressividade também é um mecanismo para aliviar suas próprias frustrações, de modo que a agressão nem sempre é evocada pelo público (TUMMERs et al., 2015).

\section{Análise sobre os efeitos sociais da implementação}

Duas novas linhas de abordagem nos estudos de implementação têm questionado a lógica mais "estadocêntrica" hegemônica e partem da ideia de que a implementação não pode ser vista sempre como uma abordagem do Estado. Para os teóricos desse campo, a implementação é um processo de interação e nessa implementação acontecem múltiplas negociações que não são consideradas quando é utilizada a lógica puramente estadocêntrica. Essa negociação depende da posição social dos dois (ou mais) indivíduos nela envolvidos.

Uma das inovações desse campo é atentar para a necessidade de se enxergar o burocrata como mais além de apenas um agente do Estado - mas sim uma pessoa com sua trajetória individual, que frequenta certos espaços e mantém certas relações, e tudo isso é levado em consideração para entender como ele constrói essa negociação com outros indivíduos. Busca, portanto, compreender elementos mais sociológicos que influenciam o processo de implementação, especialmente aqueles relacionados às interações entre usuários e burocratas e dimensões culturais e sociológicas presentes nesse processo.

Uma primeira forma de tratar essa abordagem mais sociológica tem sido desenvolvida pela academia americana, com autores que analisam os processos de construção de julgamento, categorização e merecimento. Ela parte do diagnóstico de que a literatura tradicionalmente tomou como um pressuposto as tarefas do burocrata de nível de rua de despersonalizar e categorizar o usuário de uma política. No entanto seria necessário analisar o potencial de inclusão ou exclusão existente dentro desse processo de categorização por parte dos burocratas. Alguns autores desse campo têm chamado a atenção para o fato de que esse processo de categorização não se dá de maneira puramente automática, técnica e processual, mas sim com a influência de julgamentos e pela ideia de merecimento do próprio 
burocrata. Nesse campo, há a ideia de que os burocratas julgam e constroem níveis de merecimento que influenciam diretamente no acesso do usuário ao Estado. 0 que se analisa nesse campo é como se dá o processo de julgamento e como isso constrói formas de merecimento.

Neste sentido, os trabalhos de Maynard-Moody e Musheno (2003) são pioneiros, apontando que na atuação dos burocratas há um conjunto de fatores operando e influenciando sua ação. Esses fatores têm dimensões legais e culturais e estão em constante disputa, cabendo aos burocratas decidir como lidar com esses conflitos. Os autores trazem à luz a dimensão do julgamento realizada pelos burocratas a respeito de seu trabalho e como esse julgamento, relacionado à construção de justificativa para fazerem o que fazem, é elemento crucial no resultado da política implementada. Para eles, os burocratas consideram que as regras podem ser barreiras para fazerem o que acreditam e, nesse sentido, adaptam as regras para darem sentido ao seu trabalho, construindo justificativas que sustentem suas decisões. A discricionariedade opera, assim, num processo de classificação identitária dos usuários atendidos (determina quem são, coloca-os em grupos de pertencimento e classifica entre merecedores ou não das políticas). Suas decisões têm, portanto, uma dimensão de classificação identitária que tem como produto a capacidade de interferir nos processos de inclusão ou exclusão social dos usuários do serviço.

Uma segunda linha de estudos sobre a abordagem sociológica da implementação se filia na sociologia francesa, denominada sociologia do guichê. Esse campo procura entender, a partir das trajetórias dos indivíduos e de suas posições sociais, como as negociações existentes no processo de implementação são realizadas. Nessa visão, o resultado do processo de implementação é a política, mas também vai além disso: ele é a reconstrução das posições sociais de ambos. As implicações sociais resultantes da implementação vão para além da política em si.

Essa literatura desenvolve reflexões críticas sobre a relação entre servidores e usuários como parte de uma estrutura social mais ampla, na qual há diferentes práticas, sistemas de dominação e agência operando. Nesse sentido, Dubois (1999) aponta que a discricionariedade dos burocratas pode permitir que preconceitos de raça, gênero ou regionais se tornem premissas da implementação de políticas. Analisando a performance de burocratas do serviço social francês, Dubois (1999) demonstra como o uso da discricionariedade tem um impacto importante nas formas de acesso dos usuários. O autor assume que esses burocratas são indivíduos que possuem histórias de vida e status econômicos específicos e, ao mesmo tempo, são uma personificação do aparato burocrático, do qual se espera uma suposta impessoalidade no tratamento dos usuários. Mas, como aponta o autor, 
não existem nem burocratas impessoais nem clients padronizados. O que existem são agentes sociais com personalidades individuais e que, sob certas condições e limites, precisam exercer papéis de burocratas ou de clientes impessoais ou padronizados (DuBoIs, 1999).

Dubois (1999), assim, sustenta que a construção das práticas dos burocratas no processo de implementação (que ele conceitua como materialização das políticas) depende da concepção que burocratas têm sobre seu papel, uma questão que é influenciada por questões organizacionais, mas também por status social tanto dos burocratas como dos usuários. Assim, elementos relacionados à posição social dos atores, suas trajetórias e fatores organizacionais se tornam inseparáveis para compreender como e por que os burocratas exercem a discricionariedade na construção de práticas que têm impactos inclusivos ou excludentes.

\section{Considerações finais: aportes para uma agenda brasileira de estudos de implementação}

Diversos estudos clássicos vêm apontando para a escassa literatura sobre implementação de políticas públicas no Brasil (ARRETCHE, 2001; FARIA, 2006 SOUZA, 2017; LOTTA, 2015). Ainda assim, optamos por fazer uma análise das principais revistas brasileiras do campo de administração pública e políticas públicas buscando pelo termo "implementação de políticas públicas". Embora o termo "implementação" apareça em várias revistas apenas como fase do ciclo (e não como objeto de análise), foram encontrados no levantamento apenas 21 artigos que de fato utilizaram metodologias ou análises dos estudos de implementação. Entre eles, há artigos mais voltados a discussões teóricas, outros que analisam de fato a implementação de alguns programas e outros que têm um olhar mais específico para a atuação dos burocratas de nível de rua.

A análise dessa parca literatura nacional demonstra que, à luz do que aconteceu internacionalmente no campo, ainda há muita fragmentação nos estudos sobre implementação, confirmando o diagnóstico de Saetren (2014). Ao mesmo tempo, a análise da produção nacional demonstra que há uma vasta agenda inexplorada nos temas brasileiros, na medida em que poucos estudos estão sendo realizados utilizando modelos analíticos que avancem de fato na construção da compreensão sobre o processo de implementação.

Se essa lacuna traz consequências teóricas à literatura nacional, isso se torna ainda mais crítico quando consideramos as mudanças pelas quais as políticas públicas brasileiras passaram nas últimas décadas e que demandariam maior compreensão dos processos de implementação - como os avanços na universalização de algumas políticas no pós Constituição Federal de 1988; a ampliação de atores envolvidos na 
tomada de decisão, especialmente com o avanço das temáticas de participação e controle; a tônica da accountability e do gerencialismo, entre outras. Esse conjunto de transformações, já bastante documentado na literatura nacional, não tem encontrado o devido respaldo analítico sob a ótica da implementação.

Assim, com base nessas mudanças, propomos alguns temas que poderiam nortear uma agenda de pesquisas em implementação de políticas no Brasil.

A primeira temática tem a ver com os desafios colocados pelo modelo federativo brasileiro, que combina autonomia e interdependência entre entes federativos em contexto de altas heterogeneidades e desigualdades e propostas de universalização de políticas. Pesquisas como de Arretche (2004), Menicucci e Marques (2016), Lima e D’Ascenzi (2017), Souza (2017) e Bichir, Brettas e Canato (2017) têm demonstrado as particularidades do federalismo brasileiro em diversas políticas e suas consequências em termos de provisão de serviços e redução de desigualdades. Compreender processos de implementação de políticas desenhadas nacionalmente e sua apropriação local é um dos temas importantes para a agenda nacional. 0 crescimento de políticas nacionais, seja dentro de sistemas unificados (como SUS e SUAS) ou de políticas de incentivo e indução, traz particularidades para se pensar a implementação, na medida em que há formulação centralizada (com variados graus de padronização) e espaços para adaptação local (SANTOS NUNES, 2017). Compreender essa cadeia de atores envolvidos em processos decisórios e como as decisões sobem e descem é mais um objetivo que reforça o tema nessa agenda.

A segunda agenda relevante, dado o contexto nacional, é a proposta de olhar os processos de implementação em contextos de altas heterogeneidade e desigualdade e refletir sobre o papel da implementação - seja em termos de seus arranjos institucionais, seja da atuação dos burocratas - na redução ou reprodução das desigualdades. Trabalhos como de Pires (2017), Lotta (2017), Carvalho e Oliveira (2017), Eiró (2017) e Marins (2017), inspirados pelas abordagens internacionais de análise dos efeitos sociais da implementação, têm buscado contribuir com essa tônica, principalmente analisando políticas sociais. Há ainda, no entanto, espaço para compreender de forma mais abrangente as especificidades da implementação em contextos de desigualdade e os efeitos da implementação nessas desigualdades tanto nas políticas sociais como para além delas.

Uma terceira agenda de pesquisas poderia aprofundar a compreensão do impacto da publicização de serviços na implementação de políticas. Desde a década de 1990, tem crescido significativamente a presença de organizações não estatais na implementação de políticas no Brasil, sejam elas privadas ou públicas não estatais, o que reflete a maior institucionalidade desse tipo de atuação, devido, em parte, à publicação das diferentes leis que regem os contratos de gestão com organizações 
sociais (Lei Federal no 9.637 de 1998, Lei Estadual Complementar no 846 de 1998) e do Marco Regulatório de Organizações da Sociedade Civil (MROSC - Lei no 13.019 de 2014). Existem políticas públicas brasileiras implementadas totalmente por esse tipo de organização, como é o caso do Programa Cultura Viva (BONAT, 2016), ou políticas cuja implementação é feita de forma mista, envolvendo administração direta e parcerias, como é o caso da gestão de unidades básicas de saúde no Município de São Paulo. Sendo assim, a realização de estudos comparativos sobre os dois tipos de implementação poderia elucidar bastante tópicos que vêm sendo abordados de forma muitas vezes normativa, tais como o alcance de resultados mais eficientes e a maior aderência da política às demandas do público-alvo quando a implementação é feita por organizações não estatais. Além disso, uma agenda de estudos sistemáticos deve ser estruturada sobre o tema, buscando compreender questões sobre a base de legitimidade e a natureza da atuação dessas organizações, bem como sobre os recursos utilizados e os resultados alcançados por elas.

O quarto tema que caberia é a relação entre implementação, processos participativos e sistemas de controle. Há uma vasta agenda nacional que analisa a atuação das instituições participativas principalmente na formulação e no controle das políticas. Mas compreender se e como há participação na implementação (a exemplo do papel das instituições participativas ligadas a equipamentos públicos) é ainda algo a ser aprofundado a literatura. Isso permitiria compreender em que medida as decisões da sociedade alteram processos de implementação e atuação da burocracia. A mesma pergunta poderia ser respondida analisando a atuação dos órgãos de controle sobre a implementação.

Por fim, uma agenda muito cara à realidade nacional e pouco abordada internacionalmente (foi encontrado apenas um artigo sobre este tema) é a discussão de intersetorialidade. Considerando as complexidades dos problemas públicos, a agenda nacional tem apontado a necessidade de pensarmos em soluções mais complexas e, portanto, intersetoriais para enfrentá-los (BICHIR, 2011; BRONZO, 2010; LOTTA; VAZ, 2015; LOTTA; FAVARETO, 2016). A literatura sobre intersetorialidade tem avançado em compreender como a atuação conjunta de diferentes setores pode gerar soluções mais adequadas aos problemas públicos. Um tema que ainda merece aprofundamento diz respeito à compreensão dos processos de implementação intersetoriais, que envolvem burocracias de diferentes áreas.

Consideramos, portanto, que há uma agenda grande a ser ainda avançada nos estudos nacionais, que permita compreender como e se as ditas mudanças têm sido processadas e têm promovido resultados efetivos na entrega de políticas públicas universais, com participação e controle social. Assim, a construção de um Estado provedor de serviços públicos universais no Brasil requer o crescimento 
de uma agenda de estudos que seja capaz de observar como as políticas têm sido entregues, a relação das burocracias na sua implementação, como são alteradas e os resultados que efetivamente geram para os cidadãos. Além disso, dada a agenda brasileira de políticas sociais, torna-se também necessário analisar a dimensão da pobreza e inclusão e o papel da burocracia nesse processo. Concluímos, portanto, que se faz urgente um aprofundamento dos estudos de implementação na literatura nacional, que possa não apenas se inspirar nas perspectivas internacionais, mas acima de tudo adaptá-las à nossa realidade, ao contexto nacional e ao tipo de políticas públicas que temos implementado no país.

\section{Referências bibliográficas}

Abers, Rebecca. Ativismo na burocracia? O médio escalão do Programa Bolsa Verde. In: CAVALCANTE, Pedro; LOTTA, Gabriela. Burocracia de médio escalão: perfil, trajetória e atuação. Brasília: Enap, 2015. p. 143-175.

AHN, Michael; BRETSCHNEIDER, Stuart. Politics of e-government: e-government and the political control of bureaucracy. Public Administration Review, v. 71, n. 3, p. 414424, 2011.

ALEXANDER, Damon; LEWIS, Jenny; ConSIDINE, Mark. How politicians and bureaucrats network: a comparison across governments. Public Administration, v. 89, n. 4, p. 1274-1292, 2011.

ANDREWS, Rhys et al. Representative bureaucracy and public service performance: where, why and how does representativeness work? In: PMRA PUBLIC MANAGEMENT Research Conference Aarhus UniVersity, Denmark, June 2016.

ARRETCHE, Marta. Uma contribuição para fazermos avaliações menos ingênuas. In: BARREIRA, M E CARVAlHo, M (ORGS). Tendências e perspectivas na avaliação de políticas e programas sociais. São Paulo: IEE/PUC-SP, 2001. p. 43-56.

Federalismo e políticas sociais no Brasil: problemas de coordenação e autonomia. São Paulo em perspectiva, v. 18, n. 2, p. 17-26, 2004.

AucoIn, Peter. Administrative reform in public management: paradigms, principles, paradoxes and pendulums. Governance, v. 3, n. 2, p. 115-137, 1990.

BACHARACH, Samuel; LAWLER, Edward. Power and politics in organizations. San Francisco: Jossey-Bass Inc Pub, 1980.

BARRET, Susan. Implementation studies: time for a revival? Personal reflections on 20 years of implementation studies. Public Administration, v. 82, n. 2, p. 249-262, 2004.

BARrett, Susan; Fudge, Colin (Eds.). Policy and action: essays on the implementation of public policy. Chicago: Routledge, 1981.

BAILEY, Margo. Representative bureaucracy: understanding its past to address its future. Public Administration Review, v. 64, n. 2, p. 246-249, 2004.

BEERI, Itai. Direct administration of failing local authorities: democratic deficit or effective bureaucracy? Public Money \& Management, v. 33, n. 2, p. 137-144, 2013. 
BEHAGEL, Jelle; ARTS, Bas. Democratic governance and political rationalities in the implementation of the water framework directive in the Netherlands. Public Administration, v. 92, n. 2, p. 291-306, 2014.

BEVAN, Shaun. Bureaucratic responsiveness: effects of elected government, public agendas and European attention on the UK bureaucracy. Public Administration, v. 93, n. 1, p. 139-158, 2015.

BICHIR, R. Mecanismos federais de coordenação de políticas sociais e capacidades institucionais locais: o caso do Programa Bolsa Família. Rio de Janeiro: UERJ, 2011. Tese em cência política - Universidade Estadual do Rio de Janeiro, Rio de Janeiro.

BICHIR, Renata; BRETTAS, Gabriela Horesh and CANATO, Pamella. Multi-level governance in federal contexts: the Social Assistance Policy in the City of São Paulo. Bras. Political Sci. Rev. [online]. vol. 11, n. 2, e0003. Epub July 27, 2017. ISSN 1981-3821.

BONAT, Juliana. Organizações não-governamentais na implementação de políticas públicas: entre o controle e a discricionariedade. São Bernardo do Campo: UFABC, 2016. Dissertação (Mestrado em Políticas Públicas) - Pós-graduação em Políticas Públicas, Universidade Federal do ABC, São Bernardo do Campo.

BRADBURY, Mark; Kellough, J. Edward. Representative bureaucracy: assessing the evidence on active representation. The American Review of Public Administration, v. 41, n. 2, p. 157-167, 2011.

BREWER, Brian; LEUNG, Joan; SCOTT, Ian. Value-based integrity management and bureaucratic organizations: changing the mix. International Public Management Journal, v. 18, n. 3, p. 390-410, 2015.

BRook, Douglas; KING, Cynthia. Enactment and implementation of the National Security Personnel System: policy made and policy unmade. Public Administration Review, v. 71, n. 6, p. 900-908, 2011.

BRonzo, C. Intersetorialidade, autonomia e território em programas municipais de enfrentamento da pobreza: experiências de Belo Horizonte e São Paulo. Planejamento e Políticas Públicas, Brasília, v. 35, p. 119-160, jul/dez 2010.

BRYSON, John M.; CROSBY, Barbara; StONE, Melissa. The design and implementation of cross-sector collaborations: propositions from the literature. Public Administration Review, v. 66, n. s1, p. 44-55, 2006.

BRYSON, John M.; CROSBY, Barbara; BRYSON, John K. Understanding strategic planning and the formulation and implementation of strategic plans as a way of knowing: the contributions of actor-network theory. International Public Management Journal, v. 12, n. 2, p. 172-207, 2009.

BURnS, Spencer; BRAdBuRY, Mark. President Lincoln, the Civil War, and the dawn of gender representation in the US federal bureaucracy. Public Administration Review, v. 73, n. 1, p. 188-190, 2013.

CARVAlho, C. e OLIVEIRA, M implementação de uma política educacional de combate ao fracasso escolar: percepções e ações de agentes implementadores em uma escola municipal no Rio de Janeiro. Boletim de Análise Político-Institucional, v. 13, p. 21-28, 2017. 
CAvalcante, Pedro; LotTA, Gabriela. Burocracia de médio escalão: perfil, trajetória e atuação. Brasília: Enap, 2015.

ChAREANPUNSIRIKUL, Suchada; Wood, Roy. Mintzberg, managers and methodology: some observations from a study of hotel general managers. Tourism Management, v. 23, n. 5, p. 551-556, 2002.

CHEN, Yu-Che. Improving transparency in the financial sector: e-Government XBRL implementation in the United States. Public Performance \& Management Review, $\mathrm{v}$. 37, n. 2, p. 241-262, 2013.

CuCCINIELlo, Maria et al. Coordination mechanisms for implementing complex innovations in the health care sector. Public Management Review, v. 17, n. 7, p. 1040-1060, 2015.

CURRIE, Graeme; Procter, Stephen. The antecedents of middle managers' strategic contribution: the case of a professional bureaucracy. Journal of Management Studies, v. 42, n. 7, p. 1325-1356, 2005.

DAWSON, Sandra; DARGIE, Charlotte. New public management: an assessment and evaluation with special reference to UK health. Public Management an International Journal of Research and Theory, v. 1, n. 4, p. 459-481, 1999.

DUNSIRE, Andrew. Control in a bureaucracy. Oxford: Palgrave Macmillan, 1978.

DuBoIS, Vincent. La vie au guichet: relation administrative et traitement de la misère. Paris: Economica, coll. « Études politiques », 1999.

ELLIS, Kathryn. 'Street-level Bureaucracy' revisited: the changing face of frontline discretion in adult social care in England. Social Policy \& Administration, v. 45, n. 3, p. 221-244, 2011.

ELMORE, Richard. Backward mapping: implementation research and policy decisions. Political Science Quarterly, v. 94, n. 4, p. 601-616, 1979.

EIRó, Flávio. O Programa Bolsa Família e os pobres "não merecedores": poder discricionário e os limites da consolidação de direitos sociais. Boletim de Análise Político-Institucional, v. 13, p. 65-70, 2017.

Evans, Tony. Professionals, managers and discretion: critiquing street-level bureaucracy. The British Journal of Social Work, v. 41, n. 2, p. 368-386, 2010.

EWALT, Jo Ann; JENNINGS, Edward. Administration, governance, and policy tools in welfare policy implementation. Public Administration Review, v. 64, n. 4, p. 449-462, 2004.

FARIA, Carlos Aurelio Pimenta de. Idéias, conhecimento e políticas públicas: um inventário sucinto das principais vertentes analíticas recentes. Caxambu: Associação Nacional de Pós-Graduação e Pesquisa em Ciências Sociais, 2006.

Ferrelra, Daniela. Ativismo institucional no Governo Federal: as práticas dos analistas técnicos de políticas sociais. São Bernardo do Campo: UFABC, 2016. Dissertação (Mestrado em Políticas Públicas) - Pós-graduação em Políticas Públicas, Universidade Federal do ABC, São Bernardo do Campo.

FLOYD, Steven; WoOLDRIDGE, Bill. Middle management involvement in strategy and its association with strategic type: a research note. Strategic Management Journal, 
v. 13, n. S1, p. 153-167, 1992.

GAINS, Francesca; JoHN, Peter. What do bureaucrats like doing? Bureaucratic preferences in response to institutional reform. Public Administration Review, v. 70, n. 3, p. 455-463, 2010.

GoGGIN, Malcolm et al. Studying the dynamics of public policy implementation: a third-generation approach. In: GoGGIN, Malcolm et al. Implementation and the policy process: opening up the black box, 1990. p. 19-38.

Goldfinch, Shaun; Derouen, Karl; PospiesznA, Paulina. Flying blind? Evidence for good governance public management reform agendas, implementation and outcomes in low income countries. Public Administration and Development, v. 33, n. 1, p. 50-61, 2013.

Groeneveld, Sandra; VAN DE WALle, Steven. A contingency approach to representative bureaucracy: power, equal opportunities and diversity. International Review of Administrative Sciences, v. 76, n. 2, p. 239-258, 2010.

GUNN, Lewis. Why is implementation so difficult? Management Services in Government, v. 33, n. 4, p. 169-176, 1978.

HAEDER, Simon; WeIMER, David. You can't make me do it: state implementation of insurance exchanges under the Affordable Care Act. Public Administration Review, v. 73, n. s1, 2013.

HANF, Kenneth; SCHARPF, Fritz. Interorganizational policy making: limits to coordination and central control. California: Sage Publications (CA), 1978.

HANSEN, Jesper. From public to private sector: motives and explanations for sector switching. Public Management Review, v. 16, n. 4, p. 590-607, 2014.

HARRISON, Stephen. Street-level bureaucracy and professionalism in health services. In: HuPE, Peter; HILL, Michael; Buffat, Aurélien (Eds.). Understanding Street Level Bureaucracy. Bristol: Policy Press, 2015. p. 61-78.

HEEKS, Richard; STANFORTH, Carolyne. Understanding development project implementation: an actor-network perspective. Public Administration and Development, v. 34, n. 1, p. 14-31, 2014.

HENDERSON, Alexander. Examining policy implementation in health care: rule abidance and deviation in emergency medical services. Public Administration Review, v. 73, n. 6, p. 799-809, 2013.

HICKS, Timothy. Partisan governance and policy implementation: the politics of academy conversion amongst English schools. Public Administration, v. 92, n. 4, p. 995-1016, 2014.

HJERN, Benny; PORTER, David. Implementation structures: a new unit of administrative analysis. Organization Studies, v. 2, n. 3, p. 211-227, 1981.

Hood, Christopher. The limits of administration. London; Toronto: Wiley, 1976.

HUISING, Ruthanne; SILBEY, Susan. Governing the gap: forging safe science through relational regulation. Regulation \& Governance, v. 5, n. 1, p. 14-42, 2011.

HUPE, Peter; EDWARDS, Arthur. The accountability of power: democracy and governance in modern times. European Political Science Review, v. 4, n. 2, p. $177-$ 
194, 2012.

HUPE, Peter; HILL, Michael. Street-level bureaucracy and public accountability. Public Administration, v. 85, n. 2, p. 279-299, 2007.

JACOBSON, Willow. Creating a motivated workforce: how organizations can enhance and develop public service motivation (PSM). Public Personnel Management, v. 40, n. 3, p. 215-238, 2011.

JARVIS, Mark. The black box of bureaucracy: interrogating accountability in the public service. Australian Journal of Public Administration, v. 73, n. 4, p. 450-466, 2014.

JENKINS-SMITH, Hank; SABATIER, Paul. Evaluating the advocacy coalition framework. Journal of Public Policy, v. 14, n. 2, p. 175-203, 1994.

JONES, Robert; NOBLE, Gary. Managing the implementation of public-private partnerships. Public Money and Management, v. 28, n. 2, p. 109-114, 2008

KASYMOVA, Jyldyz. A Cross-national evaluation of representative bureaucracies: implementation, challenges, and outcomes. Public Administration Review, v. 75, n. 2, p. 327-328, 2015.

KEISER, Lael. Understanding street-level bureaucrats' decision making: determining eligibility in the Social Security Disability Program. Public Administration Review, v. 70, n. 2, p. 247-257, 2010.

KIM, Pan. A theoretical overview of representative bureaucracy: synthesis. International Review of Administrative Sciences, v. 60, n. 3, p. 385-397, 1994.

KURATKO, Donald et al. A model of middle-level managers' entrepreneurial behavior. Entrepreneurship Theory and Practice, v. 29, n. 6, p. 699-716, 2005.

LAW, John; CALLON, Michael. The life and death of an aircraft: a network analysis of technical change. In: WE, Bijker; LAW, J. (Eds.). Shaping technology/building society: studies in sociotechnical change. Cambridge, MA: MIT Press, 1992. p. 21-52.

LEWIS, Gregory. Men and women toward the top: backgrounds, careers, and potential of federal middle managers. Public Personnel Management, v. 21, n. 4, p. 473-492, 1992.

LIM, Hong-Hai. Representative bureaucracy: rethinking substantive effects and active representation. Public Administration Review, v. 66, n. 2, p. 193-204, 2006.

LIMA, Luciana; D'ASCENZI, Luciano. O papel da burocracia de nível de rua na implementação e (re)formulação da Política Nacional de Humanização dos serviços de saúde de Porto Alegre (RS). Revista de Administração Pública, v. 51, n. 1, p. 4663, 2017.

LIPSKY, Michael. Street level bureaucrats. Nova York: Russel Sage, 1980.

. Street-level bureaucracy, 30th Ann. Ed.: Dilemmas of the individual in public service. Nova York: Russell Sage, 2010.

LOTTA, Gabriela. Burocracia e implementação de políticas de saúde. Rio de Janeiro: Editora Fiocruz, 2015.

Inclusão, exclusão e (re)produção de desigualdades: o papel das práticas, interações e julgamentos dos agentes comunitários de saúde na implementação 
das políticas públicas. Boletim de Análise Político-Institucional, v. 13, p. 15-20, 2017. LOTTA, Gabriela; PAVEZ, Thais. Agentes de implementação: mediação, dinâmicas e estruturas relacionais. Cadernos Gestão Pública e Cidadania, v. 15, n. 56, 2010.

LOTTA, Gabriela; VAZ, José. Arranjos institucionais de políticas públicas: aprendizados a partir de casos de arranjos institucionais complexos no Brasil. Revista do Serviço Público, v. 66, n. 2, p. 171-194, 2015.

LotTA, Gabriela; FAVARETo, Arilson. Desafios da integração nos novos arranjos institucionais de políticas públicas no Brasil. Revista de Sociologia e Política, v. 24, n. 57, p. 49-65, 2016.

MARINS, Mani. Symbolic and gender boundaries among the Bolsa Familia Beneficiaries. Sociology and Anthropology, v. 5, p. 635-644, 2017.

MARQUES, Eduardo. Redes sociais, instituições e atores políticos no governo da cidade de São Paulo. São Paulo: Annablume, 2003.

MAYNARD-Moody, Steven; Musheno, Michael. Cops, teachers, counselors: Stories from the front lines of public service. Michigan: University of Michigan Press, 2003.

Social equities and inequities in practice: street-level workers as agents and pragmatists. Public Administration Review, v. 71, n. S1, p. 16-23, 2012.

MEIER, Kenneth; Nicholson-CROTTY, Jill. Gender, representative bureaucracy, and law enforcement: the case of sexual assault. Public Administration Review, v. 66, n. 6, p. 850-860, 2006.

MEIER, Kenneth; O'TOOLE, Laurence. Bureaucracy in a democratic State: a governance perspective. Baltimore: JHU Press, 2006.

MENICUCCI, Telma; MARQUES, Alisson. Cooperação e coordenação na implementação de políticas públicas: o caso da saúde. Dados, v. 59, n. 3, p. 823-865, 2016.

MEYER, Renate et al. Of bureaucrats and passionate public managers: institutional logics, executive identities, and public service motivation. Public Administration, v. 92, n. 4, p. 861-885, 2014.

Mingus, Matthew. Updating the democracy-bureaucracy conundrum. Public Administration Review, v. 68, n. 5, p. 932-933, 2008.

MinTZBERG, Henry. The nature of managerial work. New York: Harper \& Row, 1973. MOSHER, Frederick. Democracy and the public service. Oxford: Oxford University Press on Demand, 1982.

PALUMBo, Dennis; CALISTA, Donald. (Eds.). Implementation and the policy process: opening up the black box. Westport: Greenwood Press, 1990.

PAPAdopoulos, Thanos; Meral, Yasmin. Stakeholder network dynamics and emergent trajectories of Lean implementation projects: a study in the UK National Health Service. Public Money and Management, v. 28, n. 1, p. 41-48, 2008.

PAvez, Thais. Políticas públicas e ampliação do capital social em comunidades segregadas: o Programa Santo André Mais Igual. São Paulo: USP, 2006. Dissertação (Mestrado em Ciência Política) - Faculdade de Filosofia, Letras e Ciências Humanas, Departamento de Ciência Política, Universidade de São Paulo, São Paulo. 
PetTINICCHIO, David. Institutional activism: reconsidering the insider/outsider dichotomy. Sociology Compass, New Jersey, v. 6, n. 6, p. 499-510, 2012.

PETERS, Guy. Bureaucracy and democracy in the modern state. Public Administration Review, v. 70, n. 4, p. 642-643, 2010.

Pinto, Rogerio; OliveIRA, Jose Antonio Puppim de. Implementation challenges in protecting the global environmental commons: the case of climate change policies in Brazil. Public Administration and Development, v. 28, n. 5, p. 340-350, 2008.

PIRES, Roberto. Burocracia, discricionariedade e democracia: alternativas para o dilema entre controle do poder administrativo e capacidade de implementação. Cadernos Gestão Pública e Cidadania, v. 14, n. 54, p. 147-188, 2009. - Implementando desigualdades? Introdução a uma agenda de pesquisa sobre agentes estatais, representações sociais e (re)produção de desigualdades. Boletim de Análise Político-Institucional, v. 13, p. 7-14, 2017.

PIOTROWSKI, Suzanne et al. Key issues for implementation of Chinese open government information regulations. Public Administration Review, v. 69, n.1, 2009. PRESSMAN, Jeffrey; WILDAVSKY, Aaron. Implementation: how great expectations in Washington are dashed in Oakland: or, why it's amazing that federal programs work at all, this being a saga of the Economic Development Administration as told by two sympathetic observers who seek to build morals on a foundation of ruined hopes. Oakland: Univ of California Press, 1984.

SABATIER, Paul. The advocacy coalition framework: revisions and relevance for Europe. Journal of European public policy, v. 5, n. 1, p. 98-130, 1998.

SABATIER, Paul; MAZMANIAN, Daniel. The conditions of effective implementation: a guide to accomplishing policy objectives. Policy Analysis, p. 481-504, 1979.

SAETREN, Harald. Implementing the third generation research paradigm in policy implementation research: an empirical assessment. Public Policy and Administration, v. 29, n. 2, p. 84-105, 2014.

SAGER, Fritz et al. Street-level bureaucrats and new modes of governance: how conflicting roles affect the implementation of the Swiss Ordinance on Veterinary Medicinal Products. Public Management Review, v. 16, n. 4, p. 481-502, 2014.

SAIDEL, Judith; Loscocco, Karyn. Agency leaders, gendered institutions, and representative bureaucracy. Public Administration Review, v. 65, n. 2, p. 158-170, 2005.

SANTIAGO, Ariadne. Capacidades burocráticas na prática: o licenciamento ambiental através das lentes dos analistas do Ibama. Brasília: UnB, 2017. Dissertação (Mestrado em Ciência Política) - Instituto de Ciência Política da Universidade de Brasília.

SANTOS NUNES, Ana Carolina. Análise de arranjos de implementação de políticas públicas de enfrentamento à violência contra mulheres em municípios de pequeno porte. Revista do Serviço Público, v. 68, n. 3, p. 503-532, 2017.

ScoTT, Frank. Rethinking governance and bureaucracy: down with the King? Public Administration Review, v. 66, n. 1, p. 153-154, 2006.

SHARMA, Aradhana; GUPTA, Akhil (Eds.). The anthropology of the State: a reader. New Jersey: John Wiley \& Sons, 2009. 
SHEA, Jennifer. Taking nonprofit intermediaries seriously: a middle-range theory for implementation research. Public Administration Review, v. 71, n. 1, p. 57-66, 2011. SouzA, Celina. Políticas públicas: uma revisão da literatura. Sociologias, Porto Alegre, vol. 8, n. 16, p. 20-45, 2006.

Bureaucracy and policy implementation: book review. Brazilian Political Science Review, v. 10, n. 3, p. 1-3, 2017.

SOWA, Jessica; SELDEN, Sally. Administrative discretion and active representation: an expansion of the Theory of Representative Bureaucracy. Public Administration Review, v. 63, n. 6, p. 700-710, 2003.

STRUYK, Raymond. Factors in successful program implementation in Russia during the transition: pilot programs as a guide. Public Administration and Development, $\mathrm{v}$. 27, n. 1, p. 63-83, 2007.

SUTCLIFFE, Kathleen. A review of: "From Pablo to Osama: trafficking and terrorist networks, government bureaucracies, and competitive advantage by Michael Kenney". University Park, PA: Pennsylvania State University Press, 2007. 293 pages. ISBN 9870271029313. 2007.

THOMAS, Robyn; LINSTEAD, Alison. Losing the plot? Middle managers and identity. Organization, v. 9, n. 1, p. 71-93, 2002.

TUMmers, Lars; BeKKers, Victor; VINK, Evelien; Musheno, Michael. Coping during public service delivery: a conceptualization and systematic review of the literature. Journal of Public Administration Research and Theory, v. 25, n. 4, p. 1099-1126, 2015.

VIE, Ola Edvin. Have post-bureaucratic changes occurred in managerial work? European Management Journal, v. 28, n. 3, p. 182-194, 2010

WANG, Xiaohu; CHEN, Kai; BERMAN, Evan. Building network implementation capacity: evidence from China. International Public Management Journal, v. 19, n. 2, p. 264291, 2016.

WILKINS, Vicky; WILLIAMS, Brian. Black or blue: racial profiling and representative bureaucracy. Public Administration Review, v. 68, n. 4, p. 654-664, 2008.

WIMBUSH, Erica. Implementing an outcomes approach to public management and accountability in the UK-are we learning the lessons? Public Money \& Management, v. 31, n. 3, p. 211-218, 2011.

Witesman, Eva; Walters, Larry; Christensen, R. Public service motivation, public service ethos and public service values: a comparison. In: INTERNATIONAL RESEARCH CONFERENCE: One step beyond-refining public service motivation theory and research methods. Utrecht University, the Netherlands. 2013.

YESILKAGIT, Kutsal; CHRISTENSEN, Jørgen. Institutional design and formal autonomy: political versus historical and cultural explanations. Journal of Public Administration Research and Theory, v. 20, n. 1, p. 53-74, 2009.

ZUBEK, Radoslaw; STARoŇOVÁ, Katarina. Organizing for EU implementation: the Europeanization of government ministries in Estonia, Poland, and Slovenia. Public Administration, v. 90, n. 4, p. 937-956, 2012. 


\section{Gabriela Spanghero Lotta}

Doutora em Ciência Política pela Universidade de São Paulo (USP). Atualmente é professora e pesquisadora de Administração Pública e Governo da Fundação Getulio Vargas (FGV), professora da pós-graduação em Políticas Públicas da Universidade Federal do $A B C$ (UFABC), além de docente na Escola Nacional de Administração Pública (Enap). Contato: gabriela.lotta@gmail.com

\section{Ana Carolina Nunes}

Mestre em Políticas Públicas pela Universidade Federal do ABC (UFABC). Contato: ananunes14@gmail.com Sergio Cavalcanti

Graduado em Ciência Política pela Universidade Federl de Pernambuco (UFPE), mestrando em Políticas Públicas Pela Universidade Federal do ABC (UFABC). Atualmente é técnico na Fundação Abrinq. Contato: sergiomcf92@ gmail.com

\section{Daniela Damiati Ferreira}

Mestre em Políticas Públicas pela Universidade Federal do ABC (UFABC). Contato: daniela.damiati@gmail.com Juliana Bonat

Mestre em Políticas Públicas pela Universidade Federal do ABC (UFABC). Analista de Políticas Públicas e Gestão Governamental da Prefeitura de São Paulo. Contato: juliana.bonat@gmail.com 
